\title{
EFFECT OF MAGNESIUM SULFATE (A LAXATIVE) ON ACCOMMODATION AND CONVERE GENCE FUNCTION
}

\author{
BY
}

OSUDE-UZODIKE, E. B. AND AKANOH, R. N. DEPARTMENT OF OPTOMETRY, ABIA STATE UNIVERSITY

UTURU, ABIA STATE, NIGERIA

Email:ebeluzo@yahoo.com

*Corresponding author

\begin{abstract}
Magnesium sulfate ( $\left.\mathrm{MgSO}_{4}\right)$, a laxative and over-the-counter drug is abusively used by individuals to relieve constipation, hard and inconsistent stool, and after effect of poor diet. Thirty young volunteers of both sexes were administered $15 \mathrm{~g}$ of $\mathrm{MgSO}_{4}$ effervescence laxative. The effect of the drug on accommodation, accommodative convergence laccommodation $(A C / A)$ ratio, near point of convergence (NPC) and lateral phoria at far and near were studied by measuring these visual functions pre and post $\mathrm{MgSO}_{4}$ administration. Results showed that there was no effect on accommodation, NPC decreased with a peak percentage decrease of $27.5 \%$, lateral phoria at far had peak percentage decrease of $375.4 \%$, lateral phoria at near had peak percentage decrease of $50.9 \%$ and $A C / A$ ratio a percentage decrease of $43.4 \%$. These effects were found to be significant $(P<0.05)$. Eye care practitioners should advise their patients to desist from abusing laxatives and other over-the-counter drugs and should consider its effects during analysis of visual test finding for effective patient care.
\end{abstract}

KEYWORDS: Magnesium sulfate, Laxatives, Accommodation, Convergence, Near point of convergence, Lateralphoria.

\section{INTRODUCTION}

Laxatives of various types are widely prescribed and more widely purchased without prescription indicating a cultural pre-occupation with ñregularityòof intestinal walls and stool ${ }^{1}$. They are generally described as over-the-counter (OTC) products $^{2}$.

Laxative drugs that affect the fecal constituent accelerate elimination of stool from the rectum ${ }^{3}$. They can be used to relieve constipation during pregnancy, in those whose bowel motility has been altered through use of anticholinergic drugs, narcotics, antihelmintic therapy and generally short-term treatment of constipation ${ }^{4}$ and other possible conditions that can lead to constipation like condition within the colon and rectum or externally ${ }^{5,6,7}$. The external conditions can be as a result of poor dietary habits (most common), medications and psychological factors. Bowelconscious individuals easily abuse laxatives. Laxatives like other being an OTC drugs, the result may be similar to simple, prolonged diarrhea with symptoms of potassium ion $(\mathrm{K}+)$ depletion, intestinal hypotonus, alkalosis and muscle weakness ${ }^{8}$. The use of laxatives may become habitual and can lead to hyponatremia, loss of the rectal reflex and laxatives dependent constipation ${ }^{3}$. Chronic use of laxatives can become habituating leading to the development of a dilated atonic laxative colon, which requires increasing laxative use with little success ${ }^{5,6}$.

Magnesium sulfate also known as Epsom salt or bitter salt ${ }^{9}$ is a hydrate salt with a chemical name of magnesium sulfate heptahydrate ${ }^{9,10}$. Chemical formula is $\mathrm{MgSO}_{4} \cdot 7 \mathrm{H}_{2} \mathrm{O}^{11}$ and trade name is Andrews liver salt.

Dried magnesium sulfate is an osmotic laxative $e^{4,11}$ or a saline laxative $e^{12,13}$ that acts by increasing the bulk of the stools through attracting and holding large amounts of fluids, the increased bulk results in the mechanical stimulation of peristalsis ${ }^{4}$.

Systemically administered drugs are known to produce effect in the eye when sufficient concentration of the drug reaches its site of action in the eye and can influence various clinical procedures and visual test results.

The adverse effect of $\mathrm{MgSO}_{4}$ in the body system can also affect the eyes hence it is worthwhile that the ocular and visual effects (if any) are known by the primary eye-care practitioners for better patient management. 


\section{MATERIALS AND METHOD}

Effect of magnesium sulfate on accommodation and convergence functions is a prospective and clinically based study. Abia State University Optometry Clinics (Uturu and Umuahia) were used for the study. Thirty healthy volunteers between the ages of 18 and 34years were used. Those volunteers with ocular pathology, refractive error and history of systemic abnormalities were screened out as such conditions might jeopardize the test results. Experimental subjects were well fed during the period of the study and they served as their own control.

The visual functions of interest: accommodation (using minus-lens-to-blur method), lateral phoria (using Von-Graefe technique), NPC (using PD rule) and AC/A ratio (using the induced phoria method) were measured pre and post $\mathrm{MgSO}_{4}$ administration. The research lasted for a period of 3days. Pilot study showed that systemic effects start 2hours after $15 \mathrm{~g} \mathrm{MgSO}_{4}$ ingestion, hence, measurement of visual functions started 2hours post administration of $15 \mathrm{~g} \mathrm{MgSO}_{4}$ on volunteer subjects. The visual functions were reassessed at intervals of 30 minuts till 2 hours after $\mathrm{MgSO}_{4}$ ingestion and then once daily for the next 3days. Data obtained were analyzed using tables, figures and Z-test for significance of the result.

Magnesium sulfate used was manufactured from Glaxo Smith Kline (Nig. PLC) with batch no. 034E.

\section{RESULTS}

The test substance, Magnesium sulfate heptahydrate was administered on volunteer subjects and its effect on visual functions of interest was measured. The analysis of the data obtained is presented below. The symbol used in the graphs: Y1, Y2, Y3, Y4, Y5, Y6, Y7, Y8, represents 2hours, 21/2hrs, 3hrs, 31/2hrs, 4hrs, $41 / 2 \mathrm{hrs}, 24 \mathrm{hrs}$, $48 \mathrm{hrs}$, and $72 \mathrm{hrs}$ post ingestion of magnesium sulfate respectively.

Fig. 1 showed that $\mathrm{MgSO}_{4}$ has no effect on Amplitude of Accommodation (A.A). When the data obtained was subjected to statistical analysis, $\mathrm{Z}_{\text {tab }}\left(1.96_{0.05}\right)$ was found to be greater than $\mathrm{Z}_{\text {cal }}(0.32)$ confirming the graphical representation.

NPC deceased gradually from 2 hours after magnesium sulfate intake by $1.32 \mathrm{~cm}$, peak decrease was obtained $4 \mathrm{hrs}$ after intake with induced change of $-2.8 \mathrm{~cm}$ and percentage induced change of $27.59 \%$. It started to increase from $24 \mathrm{hrs}$ post ingestion and returned to baseline value 72hours post ingestion (see fig. 2). $\mathrm{Z}_{\text {cal }}$ (8.819) was found to be greater than $\mathrm{Z}_{\text {tab }}\left(1.96_{0.05}\right)$, hence, it was concluded that ingestion of $15 \mathrm{~g}$ of $\mathrm{MgSO}_{4}$ had significant effect on NPC. The minus signs showed that the values were less than the baseline value.

Analysis of data obtained showed that lateral phoria at far decreased gradually from $2 \mathrm{hrs}$ after $\mathrm{MgSO}_{4}$ intake by $-0.82 \pm 0.16 \mathrm{qD}$ and had a peak decrease $4 \mathrm{hrs}$ after intake with induced change of $2.29 \pm 0.28 \mathrm{qD}$. The peak percentage induced change was 375 . $4 \%$. It then returned to baseline value $72 \mathrm{hrs}$ post ingestion. Fig. 3 showed the graphical representation of this effect. Statistical analysis showed a significant effect of $\mathrm{MgSO}_{4}$ on lateral phoria at far $\left(\mathrm{Z}_{\mathrm{cal}} 10.6>\mathrm{Z}_{\mathrm{tab}} 1.96\right.$ at $96 \%$ confidence interval).

Fig. 4 represents the analysis of the $\mathrm{MgSO}_{4}$ effect on lateral phoria at near. Lateral phoria at near decreased gradually from $2 \mathrm{hrs}$ after $\mathrm{MgSO}_{4}$ intake by $0.98 \pm 0.1890$. Peak induced change was obtained $4 \mathrm{hrs}$ after intake with induced change of $2.8 \pm 0.31 q D$ and percentage induced change of $50.9 \%$. It returned to baseline value $72 \mathrm{hrs}$ post ingestion. Statistically, the effect was shown to be significant $\left(\mathrm{Z}_{\mathrm{cal}} 7.68>\mathrm{Z}_{\mathrm{tab}} 1.96\right)$.

From fig. 5, AC/A ratio decreased gradually from 2 hrs after $\mathrm{MgSO}_{4}$ intake by $0.56 \pm 0.14$. Peak decrease was obtained $4 \mathrm{hrs}$ after intake with induced change of $-1.98 \pm 0.26$ and percentage induced change of $43.4 \%$. AC/A gradually increased and returned to baseline value $72 \mathrm{hrs}$ post ingestion. Statistically, the induced effect was found to be significant $\left(\mathrm{Z}_{\mathrm{cal}} 5.89>\mathrm{Z}_{\mathrm{tab}} 1.96\right)$.

\section{DISCUSSION}

Analysis of data obtained as a result of administration of $15 \mathrm{~g} \mathrm{MgSO}_{4}$, a laxative, on volunteer subjects showed no effect on amplitude of accommodation $(\mathrm{P}>0.05)$ but significant effect on NPC, lateral phoria at far and near and AC/A ratio (see figs. $2-5 ; \mathrm{P}<0.05$ ).

These effects can be explained on the stimulation of parasympathetic nervous system in stimulating peristalsis, as the bulk of the stool is increased $^{4,7,12,14,15}$. Postganglionic parasympathetic fibres stimulate accommodation while preganglionic parasympathetic fibres stimulate convergence. In both the preganglionic and postganglionic parasympathetic fibre stimulation, acetylcholine will be released ${ }^{16,17}$.

Ingestion of $\mathrm{MgSO}_{4}$ stimulates peristalsis and suppresses myenteric plexus, which is also innervated by the preganglionic parasympathetic 
system. The information is sent to the brain stem where the neurons of the reticular activating system processes the information and in turn stimulates the motor part of the vagus nerve and motor part of any other cranial nerve (oculomotor nerve inclusive). Innervations of the motor part of the oculomotor nerve led to stimulation of medial recti muscles of both eyes increasing the tonic convergence which results in decreased values of NPC and lateral phoria (far and near) tending towards esophoria (as shown in figs 2-5).

The effect of $15 \mathrm{~g} \mathrm{MgSO}_{4}$ on $\mathrm{AC} / \mathrm{A}$ ratio is a cumulative effect and is supported by Borish's ${ }^{18}$ assertion that central nervous depressants decrease $\mathrm{AC} / \mathrm{A}$ ratio by selectively reducing convergence response without affecting accommodation and that generally, the action of drugs indicate a synkinesis between accommodation and convergence and the accommodation by $\mathrm{MgSO}_{4}$ administration can be explained by the fact that ciliary body and iris sphincter muscles involved in accommodative action are supplied by autonomic fibres of oculomotor nerve not the motor fibres of oculomotor nerve which is being affected by $\mathrm{MgSO}_{4}$.

In conclusion, $\mathrm{MgSO}_{4}$ effervescence, a laxative and OTC drugs, when abused can lead to over convergence and esophoric conditions which could degenerate to binocularity problem. Primary eye care practitioners should take note of the use of over-the-counter drugs and advice patients against its abuse. They should also consider it while prescribing to the patients as it affects some visual test results.

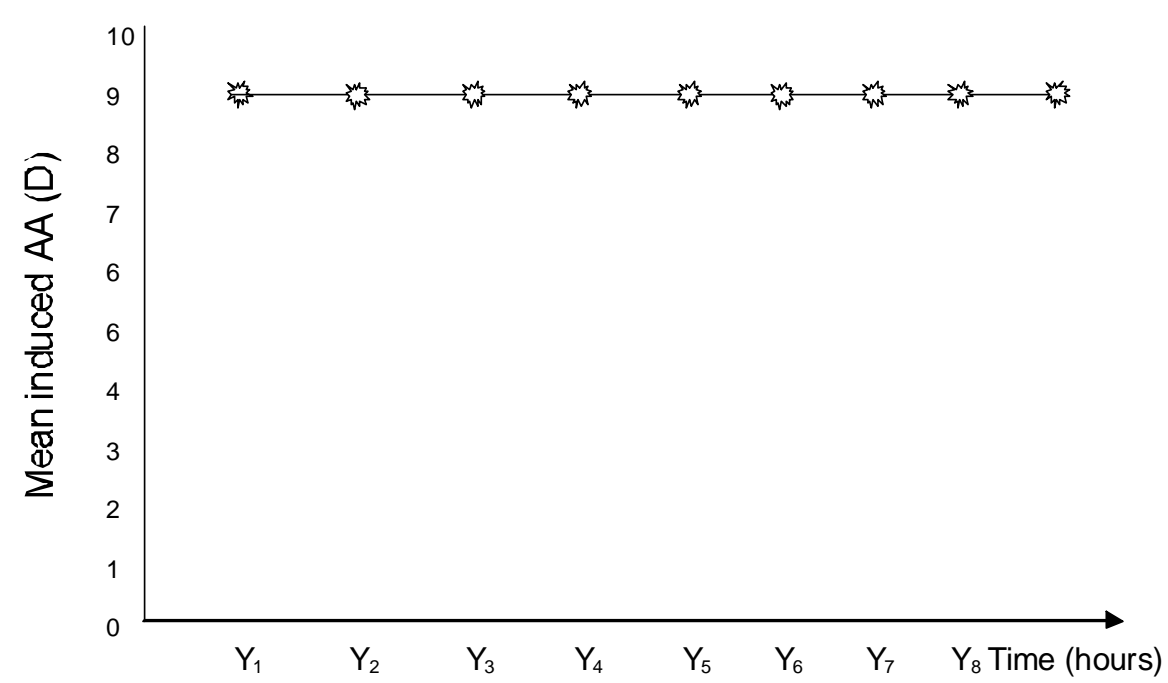

FIG 1: EFFECT OF $\mathrm{MgSO}_{4}$ ON AMPLITUDE OF ACCOMMODATION (BASELINE A .A =9.0 D)

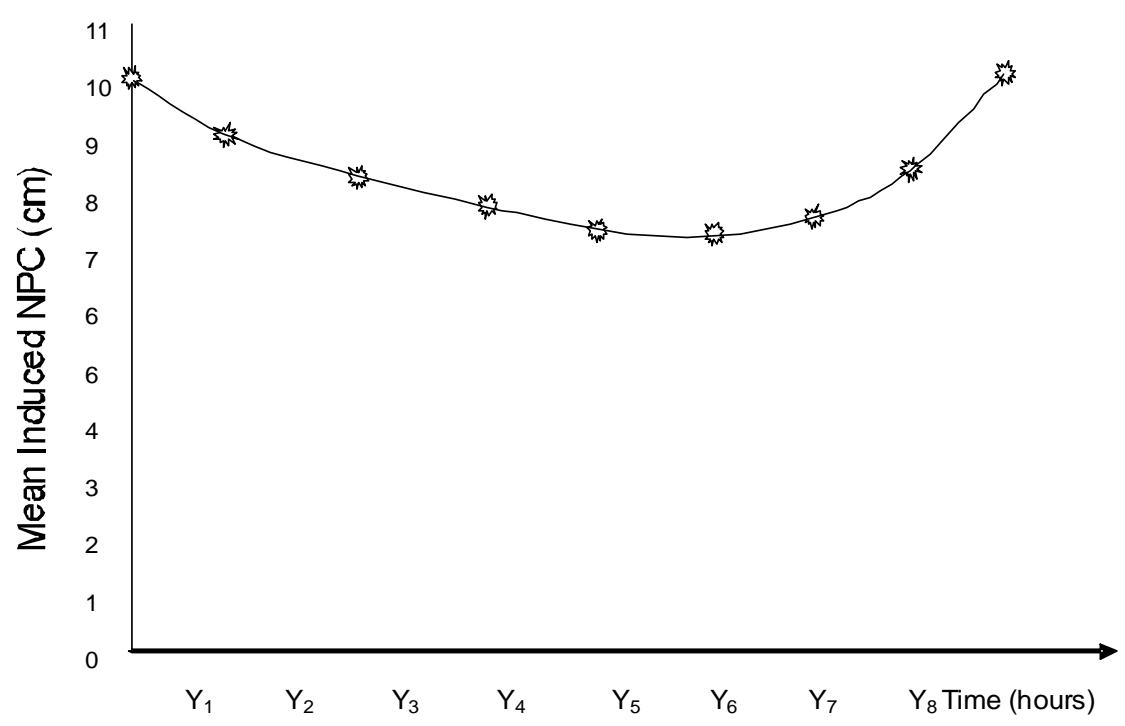

FIG 2: EFFECT OF $\mathrm{MgSO}_{4}$ ON NPC $(B A S E L I N E ~ N P C=10.15 \mathrm{c} \mathrm{m})$ 


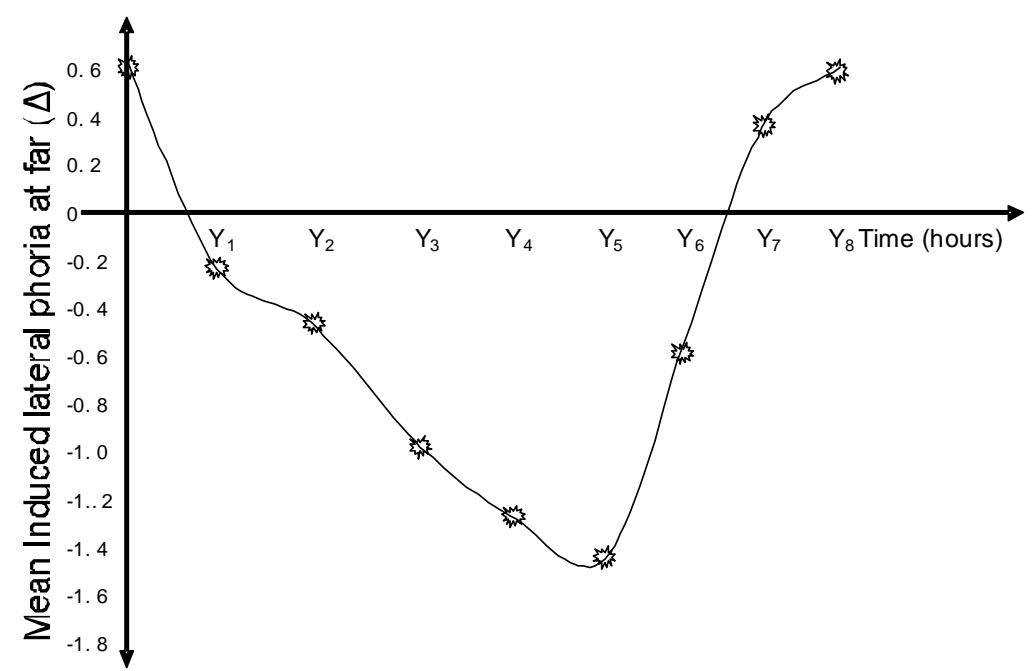

FIG. 3: EFFECT OF $\mathrm{MgSO}_{4}$ ON LATERAL PHORIA AT FAR $($ BASELINE $=0.61 \Delta)$

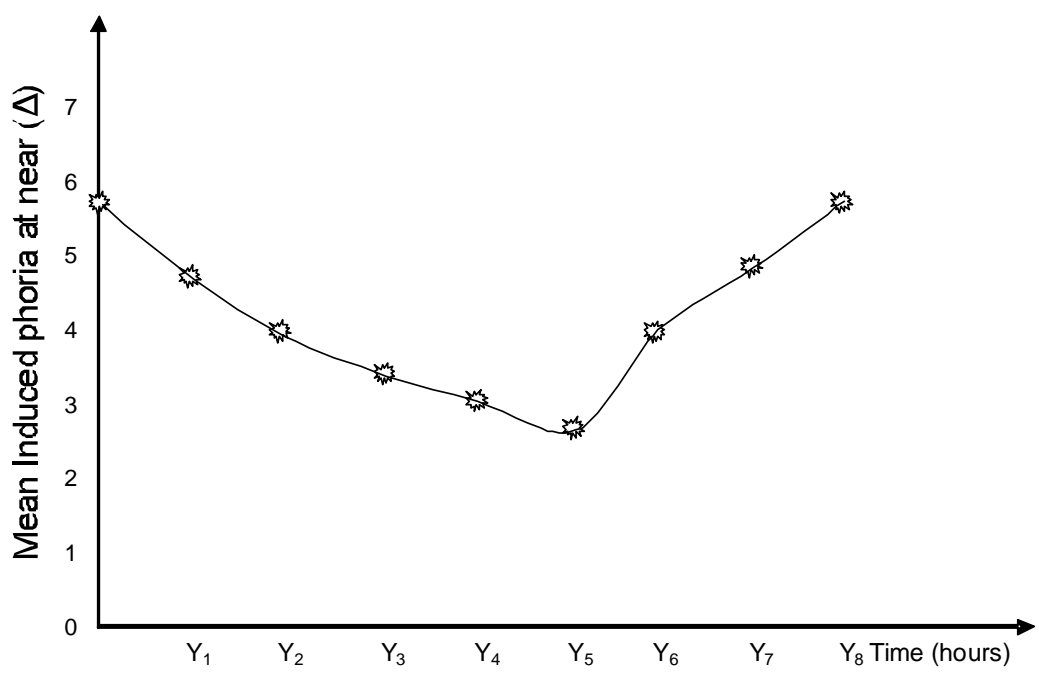

FIG. 4: EFFECT OF MgSO $_{4}$ ON LATERAL PHORIA AT NEAR (BASELINE VALUE $=5.5 \Delta$ )

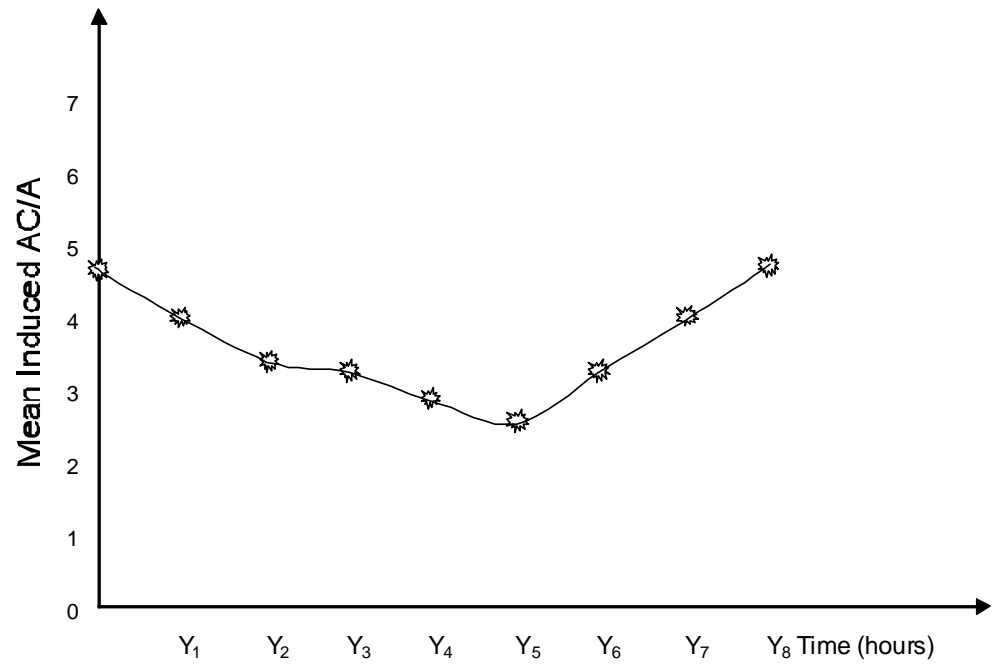

FIG. 5: EFFECT OF $\mathrm{MgSO}_{4}$ ON AC/A RATIO (BASELINE AC/A = 4.56/1) 


\section{R E F E R E N C E S}

1. Durlach, J. (1995): Magnesium. Magnes Res; 7:206-46.

2. Binder, H. J. (1997): Pharmacology of laxatives. Hoeber Haper Publishers, New York, 212pp.

3. American Medical Association (AMA) Drug Evaluations (1994): Laxatives, $3^{\text {rd }}$ Edn. PSG Publishing Company, 2000pp.

4. Lobel, S., Chane, A. N., and Battisti, L. (1996): The Nurses' drug handbook. $7^{\text {th }}$ Edn. Wiley Medical Publication, 1350pp.

5. Basson, M. D., Ronnie, F., Francisco, T., Anand, B. S. and Mechaber, A. (2003): Constipation. Wayne State University Med. J, $6: 1-30$

6. Katz, J. (2003): A new look at laxative action. Euro. J. Clin. Nutr, 56:31-46.

7. Guyton, A. C., and Power, D. W. (1994): Medical Physiology. W.B. Sanders, Philadelphia; $1217 \mathrm{pp}$.

8. Krantz, P., Dorey, P. G., Monday, K. A., Parsons, B. J. and Upsher, M. E. (1999): Medical Practice. Waverly Press, 1356pp.

9. Merck and Company (1987): Laxatives and magnesium sulfate, $6^{\text {th }}$ Edn. Merck and Company, 1056pp.
10. Durlach, J. and Durlach, V. (1994): Magnesium and therapeutics. Magnes. Res, 7:313-8.

11. British Formulary Handbook (2003): $1^{\text {st }}$ Edn. McGraw-Hill Inc, 1063pp.

12. Emdex Reference Handbook (1998): Edited by Obi C; Pharmacists and physicians drug reference handbook. $1^{\text {st }}$ Edn. Longman Group Limited, 376pp.

13. General Health Encyclopedia (1998): Laxatives. Columbia University Press, 3573pp.

14. Yamaha, T., and McColl, L. (1992): Textbook of Gastroenteriology. $6^{\text {th }}$ Edn. Philadelphia Publishers, 212pp.

15. Kumar, D., Forrest, J. N. Jr., Pike, G. and Sharp, G. W. (1994): Gastrointestinal Motility. $2^{\text {nd }}$ Edn. Churchill Livingstone, New York, $137 \mathrm{pp}$.

16. William, J. B. (1998): Borish's Clinical Refraction, $1^{\text {st }}$ Edn, W.B. Saunders Company, 3241pp.

17. Jeffery, S. C. (1998): Anomalies of Binocular Vision. $2^{\text {nd }}$ Edn. Macmillan Press, 166pp.

18 Borish, I. M. (1976): Clinical Refraction. $3^{\text {rd }}$ Edn. The Professional Press Inc, 1381pp. 